\title{
A Study of Chinese College Students' Cross-cultural Pragmatic Failure
}

\author{
Li Sheng'ai ${ }^{1, a}$, Tan $\mathrm{Xu}^{2, \mathrm{~b}}, \mathrm{Fu}$ Mingming ${ }^{3, \mathrm{c}^{*}}$ \\ ${ }^{1}$ Jilin Agricultural University, Changchun, China \\ 2 Jilin Agricultural University, Changchun, China \\ 3 Jilin Agricultural University, Changchun, China \\ a359469156@qq.com, b1040762219@qq.com, c851897659@qq.com
}

\begin{abstract}
Keywords: cross-cultural pragmatic failure; communicative competence; cross-cultural communication.
\end{abstract}

\begin{abstract}
Pragmatic failure is a frequently-discussed concept in linguistic research and English as foreign language teaching (EFLT). Learning a language means obtaining the ability of appropriately choosing linguistic forms for a specific context, or of correctly using the language in social interaction. Based on the notion of communicative competence and its significance role as the ultimate goal of EFL, this study investigates the pragmatic failure of 150 non-English majors in Jilin Agricultural University, and then makes a contrast analysis with the result got by He Ziran 30 years ago.
\end{abstract}

\section{Introduction}

With the development of science and technology, transportation and information systems enables people to have instant and constant contact with people all over the world. In order to communicate with people from different cultures appropriately as well as correctly, Chinese students need the competence both for the correctness and appropriateness of the English language. The globalization of world economy and culture necessitated the shift of major goal of ELT in China from fostering students' "Grammatical competence" to both "Grammatical competence" and "Cross-cultural communicative competence". Grammatical competence refers to the ability to produce and understand correct syntactic, lexical, and phonological forms in a language[1], while cross-cultural communicative competence means the ability to communicate with people from other different cultures. So almost in all the syllabuses of ELT, fostering students' communicative competence attracts much attention. One of the important components of communicative competence is the ability to select a linguistic form that is appropriate for a specific situation, or to use English appropriately in social interactions [2].

Since Noam Chomsky distinguished linguistic competence from linguistic performance, it had generally been assumed that the central goal of language in its broad sense including phonetics, syntax and semantics is the study of linguistic competence, or"the speaker-hearer's knowledge of his language" [3], while performance or "the actual use of language in concrete situations" (ibid), often considered as an imperfect reflection of competence, have been ignored by linguists. The distinction results in the structural approach, which has dominated language teaching for many years.

But for many years of concentrated study on phonetics, syntax and semantics - the three components of language, many linguists, have become more and more convinced that Chomsky's ideas of competence as encompassing only learners' ability to produce and understand sentences out of contexts is insufficient. And they also hold that competence should also include the ability to use language to accomplish particular communicative goals in particular social and situational environments. Especially after the American sociolinguist Dell Hymes proposes the concept of communicative competence [4], linguists and researchers became more and more aware of the significance of studying the language use. Over the last two decades, however, the discipline of linguistics has been systematically carried out far beyond the formal study of the individual sentence. Particularly, the development within the fields of functional linguistics, sociolinguistics, 
and pragmatics has opened up possibilities for a rapprochement between the studies of language form and its use. Thus, some scholars at home and abroad publish books and articles to discuss pragmatic competence, pragmatic failure and pragmatic principles.

\section{Pragmatic Failure and Communicative Competence}

Pragmatic failure was first put forward by Thomas. Thomas [5] points out that pragmatic failure has occurred on any occasion “ On which H(the hearer) perceives the force of S's(the speaker's) utterance as other than S intended she or he should perceive it”.

"Competence" as a concept originated with Chomsky in the 1960s. In 1965, Chomsky made a fundamental distinction between competence and performance. According to him, competence refers to a speaker's knowledge of the rules of his native language, while performance is what he actually produces by applying these rules.

To expand the concept of competence, Hymes (1972) argues that in addition to linguistic competence the native speaker has another rule system. That is, he knows intuitively what is socially appropriate or inappropriate and can adjust his language use to such factors as the topic, situation, and human relations involved: in short, he possesses "communicative competence". He thinks that in learning how to speak, a child must not only have a good mastery of the vocabulary and grammar of a certain language, he must also absorb the social rules that govern how he should use his vocabulary and grammar in concrete situations.

If people fail to achieve the desired communicative effect in communication, pragmatic failure will be likely to occur. It can be summarized that they are unable to understand what is meant by what is said. Pragmatic failure is more likely to occur in interactions between native and nonnative speakers, and it also occurs between native speakers. This dissertation is mainly for the discussion of the former, focusing on the pragmatic failure in intercultural communication that has hindered Chinese students' appropriate communications with native English speakers.

\section{Types of pragmatic failure}

As Thomas pointed out, pragmatic failure refers to the inability to understand "what is meant by what is said". She further divided pragmatic failures into two types: pragmalinguistic failure and sociopragmatic failure (Thomas, 1983). This distinction can, of course, cover any sort of pragmatic failures and therefore is adopted by many scholars [6] in their study of pragmatic failures. Based on their research findings, the author arranged and grouped the data collected into 3 categories, namely, pragmalinguistic failure, sociopragmatic failure, and value-related behavioral failure.

\section{Pragmalinguistic failure}

Pragmalinguistic failure occurs "when the pragmatic force mapped by a speaker onto a given utterance is systematically different from the most frequently assigned to it by a native speaker of the target language, or when speech act strategies are inappropriately transferred from L1 to L2" (Thomas, 1983). To make it easier, pragmalinguistic failures are caused by people's different understanding on a linguistic token or structure. They have something to do with linguistic features such as sentence structure and lexical connotations. Pragmalinguistic failure may arise from two identifiable sources: teaching-induced errors and pragmalinguistic transfer. The latter refers to "the inappropriate transfer of speech act strategies from one language to another, or the transferring from the source language to the target language of utterances which are semantically/syntactically equivalent, but which, because of 'interpretive bias', tend to convey a different pragmatic force in the target language.” (Thomas, 1983)

\section{Sociopragmatic failure}

Sociopragmatic failure is caused by mistakes which arise from intercultural different assessments within the social parameters affecting linguistic choice--size of imposition, social distance between speaker and hearer, relative rights and obligations, etc. Because of the different cultural backgrounds and social conventions, people respond to the same utterance differently. Chinese culture has been rooted in our mind so that we always behave according to the rules and 
principles of the society. The standards to judge what is right and what is wrong have been acquired since we were born. It's safe to say that we do things unconsciously under the control of our own culture. So when two cultures meet, the differences will result in many failures in communication. It seems like we play international chess by the rules of Chinese chess.

\section{Research Methodology}

\section{Research Objectives}

This survey is to carry out the current cross-cultural pragmatic failure of non-English major students' in 21st century in China. Pragmatic failure has received much attention from both language researchers and teachers since the early of 1980's in China. Among them, He Ziran's study in 1986 [7] contributed a lot, and is considered to be a most representational one. That study reported on a test on cross-cultural pragmatic skills and analysis the pragmatic difference in both pragmalinguistic and sociopragmatic aspects. 30 years has passed, the English learning environments in our country are improved greatly, and our EFL students are cultivated by communicative teaching approach rather than traditional pedagogy. What the typical types of cross-cultural pragmatic failure of non-English major students who have been cultivated by communicative approach in China are and whether the pragmatic failure of the language learners has reduced after so many years' teaching are the focal topics of the present study.

\section{Subject of the Investigation}

The subjects of this investigation were 150 college sophomores, mixed genders, non-English majors from different departments in Jilin Agricultural University, all of them have successfully passed the CET-4. So their linguistic competence was good enough for us to set our heart at rest and put our whole attention to investigate students' pragmatic failures more objectively. And college students will complete their EFL by the end of second year academic course, so the subjects can also present the current situation of ELT in China and show how well the educators can achieve our academic goal.

\section{Data Collection and Analysis}

Many investigations on pragmatic failure of the Chinese learners of English have been made by domestic researchers, and among them, He Ziran and Yan Zhuang's study was considered to be the most representational one. Their research contains 20 questions with 53 choices altogether. The study reported on a test on the cross- cultural pragmatic skills of 79 college teachers attending the Seminar on Linguistics and Applied Linguistics in Guangzhou Foreign Languages Institute in July, 1985. That study analyzed the cross-cultural pragmatic differences in both pramalinguistic and sociopragmatic aspects. This study made the same test on non-English major students in college to contrast to He's. The result shows the comparison of the number of failure of each choice. In order to make the comparison much clearer, the author selects 79 subjects' paper at random. Altogether there are 53 choices in the 20 questions. Among them, 44 choices of failure are declined, while only 9 of the choices are increased. And the average pragmatic failure percentage has reduced from 51\% in 1986 to 22.37\% now. Averagely, non-English major students’ pragmatic failure have improved a rapid progress, and here we should thank the communicative teaching approach and any other teaching reform as well, which teachers adopt during recent 30 years teaching. This result is considerable, and nobody can deny the affirmative effect of communicative teaching we adopt nowadays, and together with the improved English learning environments and better chances to expose to western culture as well.

\section{Summary}

Based on the statistics, we can conclude that although non-English major students' pragmatic failure situation has improved, yet there still remains pragmatic failure in communication.

From the above analyses, we can see: the current situation of non-English major students' pragmatic failure is that the students don't have a good command of the appropriate use of words, phrases, sentences and grammar; the students tend to ignore the context that the verbal 
communication depends on or transfer the customary utterances and the rules of communication from Chinese to English, so their speech acts may be contextually inappropriate, or threaten the negative face of the native English speakers, or flout the maxims of the politeness principles and cooperative principles of the western culture.

In brief, the author would like to make the conclusion of pragmatic failure as following types: 1) Misuse of vocabulary: 2) Improper use of expression; 3) Lack of knowledge of cultural differences. And among the above, the last type of pragmatic failure is most serious one.

\section{References}

[1] Tarone, E \& Yule, G (1989) Focus on Language Learner [M].Oxford: Oxford University Press, 1989.

[2][4] Hymes, D. H. On Communicative Competence [J]. Harmondsworth: Penguin, 1972.

[3] Chomsky, N. Rules and Representations. [M] Oxford: Basil Blackwell, 1980.

[5] Thomas, J. Cross-Cultural Pragmatic Failure, Applied Linguistics, Pragmatics.[M]Oxford: Oxford University Press,1983.

[6] Hu, Wenzhong \& Grove, C. L. Encountering the Chinese: A Guide for Americans [J]. Yarmouth, ME: Intercultural Press, 1991.

[7] He Zira, Yan Zhuang. On Chinese Students' Pragmatic Failure in English Communication [J]. Beijing: Foreign Languages Teaching and Research Press, 1986. 